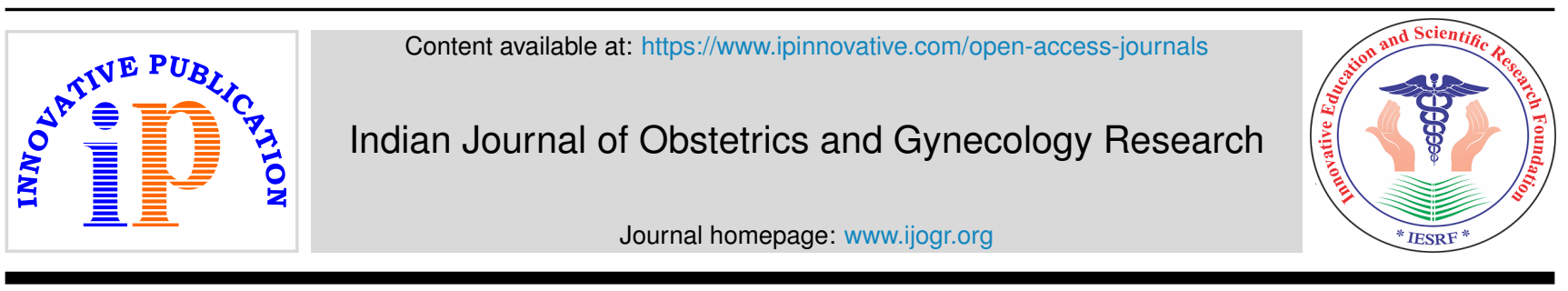

Original Research Article

\title{
Epidemiology and fetomaternal outcomes in cases of imminent eclampsia and eclampsia- retrospective study
}

\author{
Manjusha Jindal $^{1, *}$, Dweep Jindal ${ }^{1}$, Viraj Naik ${ }^{1}$, Mrinalini Sahasrabhojanee ${ }^{1}$, \\ Guruprasad Pednekar ${ }^{1}$
}

${ }^{1}$ Dept. of Obstetrics and Gynecology, Goa Medical College, Bambolim, Goa, India

\section{A R T I C L E I N F O}

\section{Article history:}

Received 16-09-2020

Accepted 02-11-2020

Available online 13-03-2021

\section{Keywords:}

Imminent eclampsia

Eclampsia

HELLP syndrome

Fetomaternal outcome

Preeclampsia

\begin{abstract}
A B S T R A C T
Context: The most common complication in pregnancy is Hypertension complicating $12-22 \%$ of all pregnancies. Among these pre-eclampsia is the leading cause constituting $10 \%$ of all pregnancies worldwide. In hospital practice in India, the incidence of pre-eclampsia varies from 5\% to $15 \%$ and of eclampsia about $1.5 \%$. According to WHO report 2008, eclampsia constitutes for $12 \%$ of all maternal deaths in developing countries. Thus it is important to study its Epidemiology and Management strategies. Settings and Design: Retrospective descriptive data based study.

Materials and Methods: The data is collected after reviewing the medical records of all gravid women with hypertensive disorder of pregnancy who presented between July 2010-July 2014. Data was collected on predesigned, standardised proforma of National Eclampsia Registry.

Statistical analysis used: Statistical analysis was performed using SPSS version 22. Data was expressed as Mean, percentages, proportions. Chi-square test was used to find association between various categorical variables. $p$-value $<0.05$ was considered to be statistically significant.

Results: During the study period there were 22,591 deliveries. There were 1468 mild and severe preeclampsia cases and 309 imminent eclampsia and eclampsia cases. The proportion of Pregnancy Induced Hypertension (PIH) cases was found to be $7.85 \%$ and that of eclampsia $1.36 \% .74 .34 \%$ of the patients belonged to age group between $20-30$ years. $69.11 \%$ patients were primigravidas with significant corelation to parity ( $\mathrm{p}$ value <.00). $68.4 \%$ cases were unbooked with $\mathrm{p}$ value $<.00 .84 .3 \%$ cases presented between 29-36 weeks. $56.96 \%$ patients had headache and $28.48 \%$ had headache with vomiting as premonitory symptoms. $74.4 \%$ patients had antepartum, $9.14 \%$ intra partum and $16.46 \%$ postpartum eclampsia. Increasing proteinuria was significantly related to no. of convulsions $(\mathrm{p}<.05)$. Maternal complications were seen in $21.68 \%$ cases. Maternal deaths during study period due to eclampsia complications were $1.3 \%$. Perinatal complications were seen in $19.41 \%$ babies; prematurity being most common (40\%). Low birth weight was seen in $68.09 \%$ babies which was statistically significant ( $\mathrm{p}$ value $<0.00$ ). There was no significant change in the incidence of eclampsia over four years.

Conclusions: Present study highlights various risk factors for pre-eclampsia. Unbooked, young primigravida with significant proteinuria are at increased risk for pre-eclampsia-related morbidity and mortality. As doctor to patient ratio is below par, the role of ASHA workers is important. Government efforts to track all pregnancies will ensure adequate antenatal care especially to the socio-economically deprived and rural population. Doctors working in peripheral hospitals should have periodic training in the management of preeclampsia and eclampsia to avoid missed opportunities as well as better transport facilities to handle obstetric emergencies.

Key Messages: As no change in incidence of eclampsia over years, ASHA workers to be trained to identify warning signs. Doctors working in peripheral hospitals should have periodic training in the management of preeclampsia and eclampsia to avoid missed opportunities.
\end{abstract}

(C) This is an open access article distributed under the terms of the Creative Commons Attribution License (https://creativecommons.org/licenses/by/4.0/) which permits unrestricted use, distribution, and reproduction in any medium, provided the original author and source are credited. 


\section{Introduction}

The most common complication in pregnancy is Hypertension complicating $12-22 \%$ of all pregnancies. Among these pre-eclampsia is the leading cause constituting $10 \%$ of all pregnancies worldwide. ${ }^{1}$ In hospital practice in India, the incidence of pre-eclampsia varies from 5\% to $15 \%$ and of eclampsia about $1.5 \% .^{2}$ National Eclampsia registry in 2014 reported the incidence of Hypertensive disorders as $10.8 \%$ and eclampsia as $1.9 \% .^{3}$ Maternal mortality worldwide is systematically reviewed by World Health Organisation (WHO) and it was reported that $16 \%$ of maternal deaths were due to hypertensive disorders in developed countries. ${ }^{4}$ According to WHO report 2008, eclampsia constitutes for $12 \%$ of all maternal deaths in developing countries. ${ }^{5}$ In Asia and Africa, hypertensive disorders constituted for $9 \%$ of maternal mortality. In India, hypertensive disorders constitute $3^{r d}$ most important cause of maternal mortality after hemorrhage and infection. ${ }^{4}$

International Society for the Study of Hypertension in Pregnancy (ISSHP) ${ }^{6}$ revised the classification for hypertensive disorders in pregnancy in 2014. Accordingly these disorders are classified as:

1. Chronic hypertension.

2. Gestational hypertension

3. Pre-eclampsia - de novo or superimposed on chronic hypertension and

4. White coat hypertension.

Preeclampsia is defined as multisystem, multi-factorial disease with Blood Pressure (B.P) reading of $\geq 140 / 90 \mathrm{~mm}$ $\mathrm{Hg}$ on two occasions 4 hours apart and $>300 \mathrm{mg}$ protein in 24 hour urine specimen after 20 weeks of gestation in a previously normotensive woman. Severe Preeclampsia is defined as B.P reading of $\geq 160 / 110 \mathrm{~mm} \mathrm{Hg}$ and $>5$ gram protein in 24 hour urine specimen or symptoms of end organ failure like derranged Liver Function Tests, thrombocytopenia, oliguria, visual disturbances, pulmonary oedema and fetal growth restriction. ${ }^{1}$ Eclampsia is defined as the development of seizures which cannot be attributed to other causes and /or unexplained coma during pregnancy or puerperium in a woman with preeclampsia. The term "eclampsia" is derived from a Greek word meaning "like a flash of lightening". Alexander Hamilton (1781) described eclampsia as a disease which always attended with the utmost hazard and frequently kills the woman like a fit of apoplexy. ${ }^{1}$ Eclampsia is most common in the third trimester and becomes more frequent near term. ${ }^{7}$ Eclampsia can be antepartum (38$53 \%)$, intrapartum $(18-36 \%)$, or postpartum $(11-44 \%){ }^{5}$ Maternal and pregnancy characteristics identified as risk factors for development of pre-eclampsia are nulliparity,

\footnotetext{
* Corresponding author.

E-mail address: manjushajindal@gmail.com (M. Jindal).
}

previous history of preeclampsia, maternal age over 40, multiple gestation, molar pregnancy, pregestational diabetes, vascular, endothelial or renal diseases, obesity and certain genetic factors. ${ }^{7}$ Various biochemical and biophysical markers have been studied to predict the development of preeclampsia. Uterine artery doppler velocimetry showing increased resistance in the late first and second trimesters is the only reliable predictive test for the development of preeclampsia. Currently no other test is reliable, valid or economical and have poor sensitivity and poor positive predictive value. Various strategies used to prevent or modify the severity of pre-eclampsia have been evaluated but none of them is found to be convincing or reproducible. ${ }^{8}$

The definitive treatment for eclampsia is delivery of the baby. ${ }^{5}$ Maternal and perinatal mortality and morbidity due to preeclampsia can be prevented by providing a good access to quality antenatal care, early diagnosis and identification of risk factors, careful monitoring and timely interventions. ${ }^{4}$ The perinatal mortality due to eclampsia is high upto the extent of about $30-50 \% .^{5}$ Poor fetal outcome is attributed to iatrogenic prematurity, respiratory distress syndrome (RDS), intrauterine asphyxia, intrauterine growth restriction (IUGR) and intrauterine death (IUD). In addition IUGR may lead to neurodevelopmental defects in children at later stages of life. ${ }^{5}$ Maternal morbidity and mortality is due to disseminated intravascular coagulation (DIC), abruptio placentae, acute kidney injury (AKI), cerebrovascular accident (CVA), cardiovascular complications, Pulmonary edema, HELLP syndrome, Retinal detachment and Aspiration pneumonia. ${ }^{1}$

The clinical management of eclampsia has gone through many changes to achieve better results. This study was undertaken to assess maternal and fetal outcome in severe Pre eclampsia, imminent eclampsia and eclampsia and to correlate various factors so as to enable us to draw out our hospital policy for management of these subjects to improve their outcome.

\section{Aims \& Objectives}

1. To study the distribution pattern of Pre eclampsia, Imminent eclampsia and eclampsia among different group of patients with special reference to age, parity, booking status, and gestational age at presentation.

2. To study maternal outcomes in terms of severity, complications and maternal mortality

3. To study fetal morbidity and mortality.

4. To study the incidence of eclampsia over 4 years

\section{Materials and Methods}

Present study is retrospective, descriptive, data based study. The data was collected by reviewing the medical records of all gravid women with hypertensive disorder of pregnancy 
managed between July 2010-July 2014. The study was approved by Institutional Ethics Committee. Preeclampsia was defined as blood pressure $\geq 140 / 90 \mathrm{mmHg}$ along with proteinuria of at least $300 \mathrm{mg} / 24$ hour after 20 weeks of gestation. The criteria to diagnose severe preeclampsia were one or more of the following: Blood pressure $\geq 160 / 110 \mathrm{mmHg}$, proteinuria of at least $5 \mathrm{gram} / 24$ hours, oliguria $<600 \mathrm{ml} / 24$ hours or $<30-50 \mathrm{ml} /$ hour, symptoms indicating end organ damage such as headache, visual disturbances, epigastric pain, medical complications such as pulmonary edema, cerebral edema, acute renal failure, hepatic hematoma, and HELLP syndrome. ${ }^{9}$ Generalized tonic clonic seizures in a preeclamptic pregnant woman, not associated with other causes was considered to be due to eclampsia.

Data was collected on predesigned, standardised proforma of National Eclampsia Registry. Demographic parameters, gestational age, associated medical diseases such as hypertension, diabetes mellitus, history of smoking, presenting complaints, blood pressure recording at admission, laboratory investigations at admission (complete blood count, liver function tests, blood urea, serum creatinine, serum uric acid and coagulation profile), 24 hours urinary protein excretion were recorded. Complications such as eclampsia, HELLP syndrome, acute renal failure, disseminated intravascular coagulation, abruptio placentae and oliguria were noted. Fetal complications like IUGR, oligohydramnios, and fetal distress was documented. Antihypertensive drugs used were alphamethyldopa, nifedipine and labetalol - both orally and parenterally, singly or in combination as needed. Cases of eclampsia received Injection Magnesium sulphate according to Pritchard regimen and imminent eclampsia received prophylactic Magnesium sulphate as per MAGPIE trial. Mode of delivery, indications for Caesarean section, obstetric factors like preterm labour and premature rupture of membranes, fetal birth weight, APGAR score at one and five minutes and requirement of NICU care were also noted. Perinatal mortality rate was defined as the number of all fetal (after 28 weeks of gestation) and neonatal (during the first 28 days after birth) deaths/1,000 births. Data was entered in epidata manager and analysed using SPSS 22 version. Data was expressed as mean, percentages, proportions. Chi-square test was used to find association between various categorical variables. p-value $<0.05$ was considered to be statistically significant.

\section{Result}

During the study period, there were 22,591 deliveries. There were 1,468 mild and severe pre-eclampsia cases and 309 imminent eclampsia and eclampsia cases. The proportion of Pregnancy Induced Hypertension (PIH) cases being 7.87\% and that of imminent eclampsia and eclampsia being $1.37 \%$.
Most of the subjects were in age group of 26-30 years that is $717(40.35 \%)$ and $17.11 \%$ were either $<20$ years or $>35$ years in age. The cases of pre-eclampsia and eclampsia were more in young age group and the relation was statistically significant (chi-square $=670.5797, \mathrm{p}$ value $<0.00$ ).(Table 1)

Out of 1777 cases, 1228(69.11\%) subjects were primigravidas and 549(30.89\%) were multigravidas. There was significant co-relation to parity. (chi-square $=185.1352$, p value $<0.00$ ). (Table 2 )

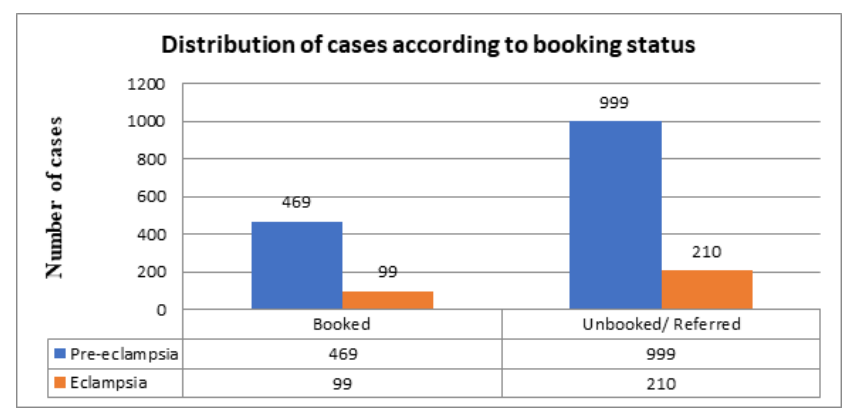

Fig. 1: Distribution of cases according to booking status

As seen in Figure 1; 568 (31.96\%) cases were booked and $1209(68.04 \%)$ cases were either unbooked or referred. Out of these, 210 cases of eclampsia were either unbooked or referred. The difference in booking status was statistically significant $($ chi square $=163.668$, $\mathrm{p}$-value $<0.00$ )

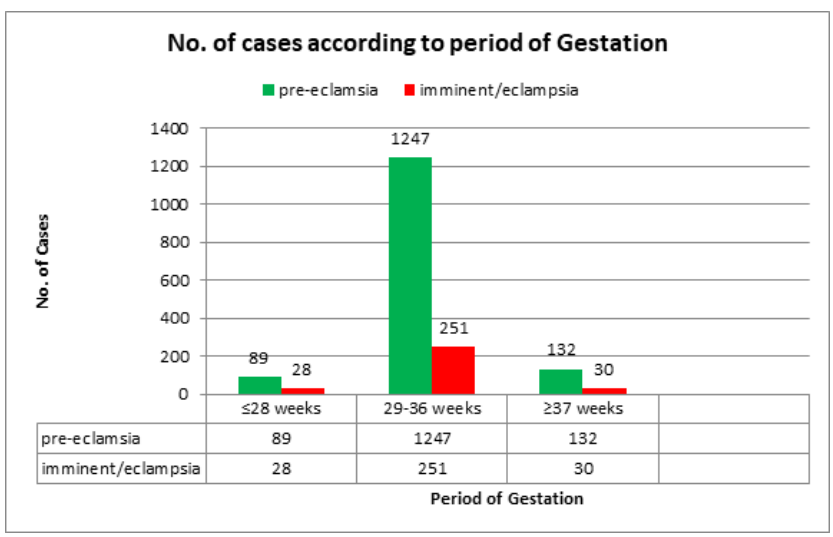

Fig. 2: Distribution of cases according to period of gestation

As seen in Figure 2, 1498 (84.3\%) patients presented at 29-36 weeks of the gestation, $117(6.58 \%)$ patients presented at less than 28 weeks of gestation and $162(9.11 \%)$ patients presented at $>37$ weeks of gestation

Figure 3 shows that more than half of the patients (56.96\%), presented with headache as premonitory symptom, followed by headache and vomiting $(28.48 \%)$, and others had headache with epigastric pain $(2.27 \%)$, headache, epigastric pain and blurring of vision (1.94\%), headache and blurring of vision (4.53\%), blurring of vision 
Table 1: Distribution of cases according to Age of patients

\begin{tabular}{lcccc}
\hline Age groups (years) & Pre-eclampsia & $\begin{array}{c}\text { Imminent } \\
\text { Eclampsia/Eclampsia }\end{array}$ & Total(N) & Percentage(\%) \\
$<20$ & 180 & 36 & 216 & $12.16 \%$ \\
$21-25$ & 499 & 105 & 604 & $33.99 \%$ \\
$26-30$ & 587 & 130 & 717 & $40.35 \%$ \\
$31-35$ & 126 & 26 & 152 & $8.55 \%$ \\
$>35$ & 76 & 12 & 88 & $4.95 \%$ \\
Total & 1468 & 309 & 1777 & $100 \%$ \\
\hline
\end{tabular}

Table 2: Distribution of cases according to Parity.

\begin{tabular}{lcccc}
\hline Parity & Pre-eclampsia & $\begin{array}{c}\text { Imminent } \\
\text { Eclampsia/Eclampsia }\end{array}$ & Total (N) & Percentage(\%) \\
Primi & 1012 & 216 & 1228 & $69.11 \%$ \\
Multi & 456 & 93 & 549 & $30.89 \%$ \\
\hline
\end{tabular}

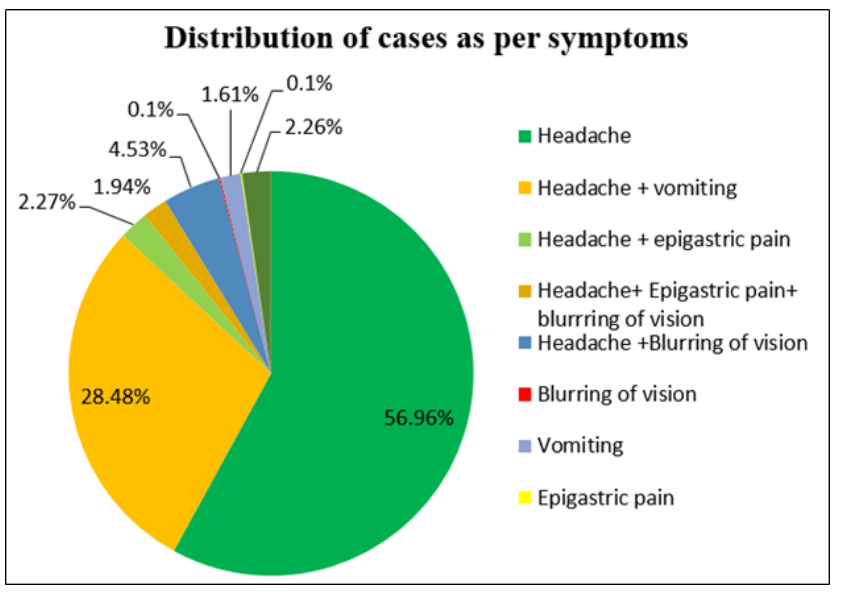

Fig. 3: Distribution of cases as per symptoms

$(0.1 \%)$, vomiting $(1.61 \%)$, epigastric pain $(0.1 \%)$ and oliguria $(2.26 \%)$.

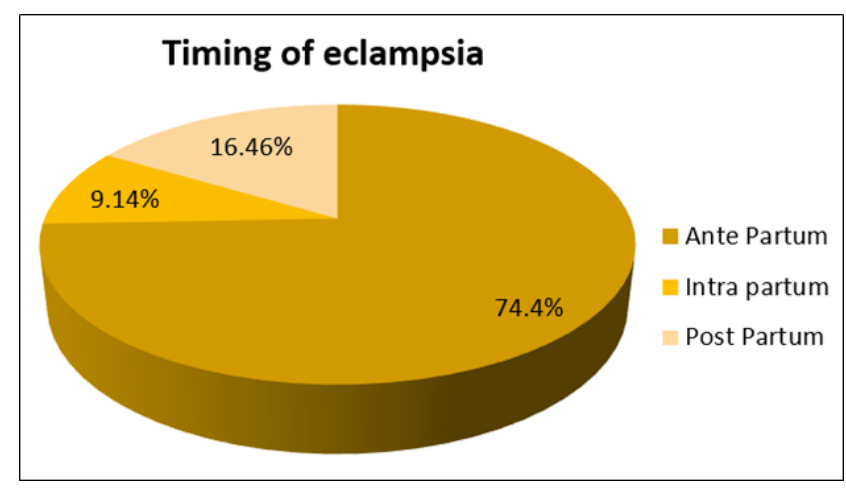

Fig. 4: Timing of eclampsia

Figure 4 shows that $74.4 \%$ patients had antepartum eclampsia, $9.14 \%$ intra partum and $16.46 \%$ had postpartum eclampsia.
Table 3 shows that $59.22 \%$ of the eclampsia patients had urinary proteins $\geq 3$ plus. $18.77 \%$ patients had deranged SGOT and SGPT. $13.59 \%$ patients had elevated LDH and $14.24 \%$ patients had elevated serum bilirubin. $13.59 \%$ of the patients had deranged blood urea and serum creatinine. $15.21 \%$ patients had raised serum uric acid. $17.80 \%$ and $18.77 \%$ of the eclampsia patients had thrombocytopenia and deranged PT INR respectively.

As per Table 4, there were 148 cases of imminent eclampsia. With increase in proteinuria there was increase in the number of convulsions. There is positive correlation between proteinuria and number of convulsions with chi square statistic 133.4668 and $\mathrm{p}$ value $<0.05$.

Table 5 shows that $38.15 \%$ patients were treated with nifedipine alone and $29.77 \%$ were treated with labetalol alone. $24.31 \%$ patients required both nifedipine and labetalol and $7.77 \%$ needed nifedipine and alpha methyl dopa for control of hypertension.

As shown in Table 6, among the preeclampsia group of patients, $57.97 \%$ delivered vaginally and $42.03 \%$ underwent Caesarean section. Among the imminent eclampsia/ eclampsia group of patients, $60.19 \%$ patients underwent Caesarean section, $35.92 \%$ delivered vaginally, $3.24 \%$ underwent assisted vaginal delivery and $0.65 \%$ required hysterotomy. This finding is significant with chi square $=$ 36.4548 and $\mathrm{P}$ - value <.00001.

Figure 5 shows that majority of patients were taken up for Caesarean section in view of previous cesarean delivery $(37.61 \%)$ and unfavourable cervix $(31.88 \%)$. Other indications for Caesarean section being failed induction (13.82\%), Doppler abnormalities (8.97\%), Cephalo Pelvic Disproportion (CPD) (4.73\%) and abruptio placentae $(2.99 \%)$.

Maternal complications were seen in 67 (21.68\%) cases. As seen in Table 7, maternal complications seen were HELLP syndrome (5.83\%), PPH (4.53\%), Abruptio placentae $(3.83 \%)$, Pulmonary edema (1.29\%) and HELLP syndrome with AKI in $1.29 \%$ cases, renal failure in $1.94 \%$ 
Table 3: Distribution of patients of eclampsia according to abnormal investigations

\section{Investigations}

1. Urinary proteins

a) $\leq+1$

b) $\geq 2+$

c) $\geq 3+$

2. Abnormal Liver Function Tests

a) SGOT

b) SGPT

c) $\mathrm{LDH}$

d) Serum Bilirubin

3. Abnormal Renal Function Tests

a) Blood urea

b) Serum creatinine

c) Serum uric acid

4. Deranged Coagulation Profile

a) Plateletcount $(<1 \mathrm{lakh} / \mathrm{cmm})$

b) Deranged PT INR

\section{Number of patients(n)}

\section{8}

88

183

58

58

42

44

42

42

47

55

58

\section{Percentage (\%)}

$12.3 \%$

$28.48 \%$

$59.22 \%$

$18.77 \%$

$18.77 \%$

$13.59 \%$

$14.24 \%$

$13.59 \%$

$13.59 \%$

$15.21 \%$

$17.80 \%$

$18.77 \%$

Table 4: Distribution of cases of imminent eclampsia and eclampsia showing relation of urinary protein to No. of convulsions

\begin{tabular}{lccc}
\hline Urinary proteins & \multicolumn{2}{c}{ Number of convulsions } & $>4$ \\
$\leq 1+$ & 0 & $1-4$ & 3 \\
$\geq 2+$ & 13 & 32 & 8 \\
$\geq 3+$ & 30 & 40 & 60 \\
Total & 105 & 90 & 71 \\
\hline
\end{tabular}

Table 5: Antihypertensive drugs used in management.

\begin{tabular}{|c|c|c|c|c|}
\hline Drugs & Pre-eclampsia & $\begin{array}{c}\text { Imminent Eclampsia/ } \\
\text { Eclampsia }\end{array}$ & Total $(\mathbf{N})$ & Percentage $(\%)$ \\
\hline Nifedipine & 560 & 118 & 678 & $38.15 \%$ \\
\hline Labetalol & 437 & 92 & 529 & $29.77 \%$ \\
\hline $\begin{array}{l}\text { Nifedipine with Alpha } \\
\text { Methyl Dopa }\end{array}$ & 114 & 24 & 138 & $7.77 \%$ \\
\hline $\begin{array}{l}\text { Nifedipine with } \\
\text { Labetalol }\end{array}$ & 357 & 75 & 432 & $24.31 \%$ \\
\hline
\end{tabular}

Table 6: Mode of delivery

\begin{tabular}{lcc}
\hline Mode of Delivery & Pre-eclampsia N(\%) & Imminent Eclampsia/ Eclampsia N(\%) \\
Normal vaginal delivery & $851(57.97 \%)$ & $111(35.92 \%)$ \\
LSCS & $617(42.03 \%)$ & $186(60.19 \%)$ \\
Assisted vaginal delivery & - & $10(3.24 \%)$ \\
Hysterotomy & - & $2(0.65 \%)$ \\
Total & $1468(100 \%)$ & $309(100 \%)$ \\
\hline
\end{tabular}

cases, DIC in $0.97 \%$ cases, ARDS, AKI with DIC, HELLP syndrome with IVH in $0.65 \%$ cases each.

As the proteinuria increased the number of feto-maternal complications also increased with a significant correlation. For maternal complications, the chi-square statistic is 10.1034. The $\mathrm{p}$ value is .006398 . For fetal complications, the chi square stastic is 7.3408 and p value is .025467 .

There were 4 maternal deaths during study period due to eclampsia complications $(1.3 \%)$.
Patients with pre-eclampsia and eclampsia delivered babies with low birth weight and this finding was found to be statistically significant (chi-square statistic 439.2834; $\mathrm{p}$-value $<0.00$ ) with significance of $\mathrm{p}$-value at $<0.05$. The distribution of cases according to birth weight is shown in Table 9.

There were 285 cases of perinatal complications in cases of pre-eclampsia and 60 cases of perinatal complications in eclampsia group amounting to $19.41 \%$ in both the groups. The perinatal complications are shown in Table 10. 
Table 7: Maternal complications in patients with imminent eclampsia and eclampsia

\begin{tabular}{lcc}
\hline Maternal Complication & Number of cases (N) & Percentage $(\%)$ \\
ARDS & 2 & $0.65 \%$ \\
Pulmonary edema & 4 & $1.29 \%$ \\
DIC & 3 & $0.97 \%$ \\
Renal failure & 6 & $1.94 \%$ \\
Abruptio placentae & 12 & $3.83 \%$ \\
HELLP Syndrome & 18 & $5.83 \%$ \\
AKI with DIC & 2 & $0.65 \%$ \\
HELLP Syndrome with Intra Ventricular Hemorhage & 2 & $0.65 \%$ \\
(IVH) & & $4.53 \%$ \\
Post Partum Hemorrhage (PPH) & 14 & $1.29 \%$ \\
HELLP Syndrome with AKI & 4 &
\end{tabular}

(ARDS- Adult Respiratory distress syndrome)

Table 8: Correlation between urinary proteins andfeto-maternal complication

\begin{tabular}{lcccc}
\hline Urinary Proteins & $\leq \mathbf{1 +}$ & $\mathbf{2 +}$ & $\mathbf{3 +}$ & Total (N) \\
Maternal complications & 4 & 7 & 56 & 67 \\
Fetal complications & 2 & 10 & 48 & 60 \\
\hline
\end{tabular}

Table 9: Distribution of cases according to Fetal birth weight

\begin{tabular}{lcccc}
\hline Birth weight(kg) & Pre-eclampsia cases & $\begin{array}{c}\text { Imminent eclampsia/ } \\
\text { Eclampsia cases }\end{array}$ & Total (N) & Percentage (\%) \\
1) $<1.5$ & 484 & 103 & 587 & $33.03 \%$ \\
2) $1.5-2$ & 303 & 62 & 365 & $20.54 \%$ \\
$3)$ 2- 2.5 & 213 & 45 & 258 & $14.52 \%$ \\
$4)>2.5$ & 468 & 99 & 567 & $31.91 \%$ \\
\hline
\end{tabular}

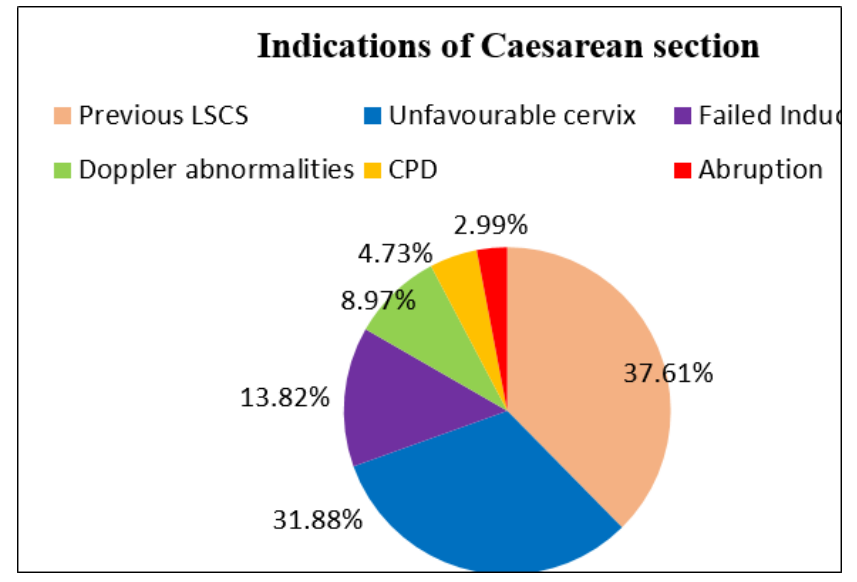

Fig. 5: Indications of LSCS

Prematurity was the most common perinatal complication in both the groups. There is significant statistical corelation between perinatal complications and pre-eclampsia and eclampsia (chi-square statistic 43.219; p-value <0.00)

The Perinatal mortality was found to be $18 \%$. The no. of cases were analysed per year. Figure 6 shows the distribution of cases. There was increase in no. of cases detected in successive years. As the cases of imminent aclampsia and eclampsia were analyzed, it was noticed that more cases were detected with imminent eclampsia than eclampsia though the relation was not significant (chi square $=6.4849, \mathrm{p}=.37$ ).

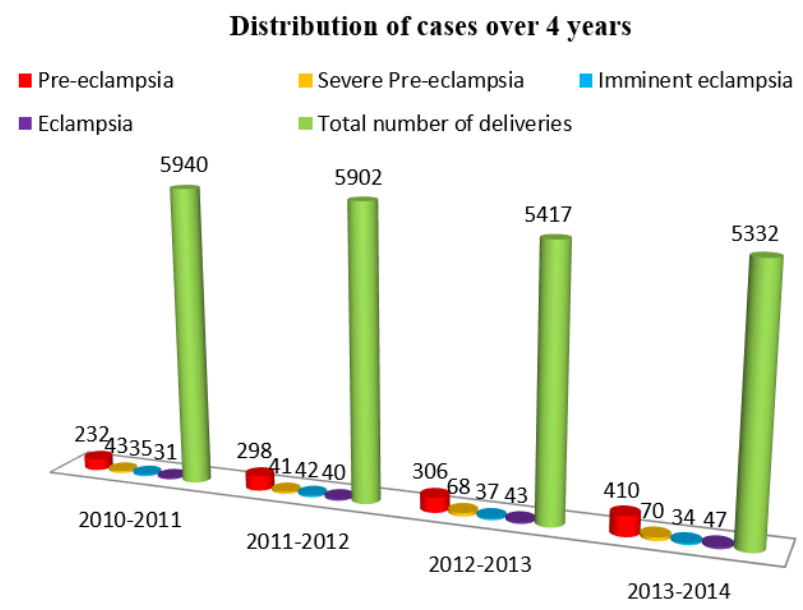

Fig. 6: Distribution of cases of pre-eclampsia and eclampsia over 4 years 
Table 10: Perinatal complications

\begin{tabular}{|c|c|c|c|c|}
\hline Complications & Pre-eclampsia & $\begin{array}{c}\text { Imminent eclampsia/ } \\
\text { Eclampsia }\end{array}$ & Total(n) & Percentage $(\%)$ \\
\hline 1. Prematurity & 114 & 24 & 138 & $40 \%$ \\
\hline 2. RDS & 85 & 18 & 103 & $29.86 \%$ \\
\hline 3. Birth Asphyxia & 37 & 8 & 45 & $13.04 \%$ \\
\hline 4. IUGR/MAS & 49 & 10 & 59 & $17.10 \%$ \\
\hline
\end{tabular}

(MAS- Meconium Aspiration Syndrome).

\section{Discussion}

Hypertension can complicate pregnancy and lead to additional problems during pregnancy. These complications have long term effects on both mother and fetus. In our study we found the proportion of Pregnancy Induced Hypertension as $7.87 \%$ and that of eclampsia as $1.37 \%$. Findings of our study are comparable to the findings of Nobis PN who reported an incidence of pre-eclampsia in hospital practice in India as 5 to $15 \%$ and that of eclampsia as $1.46 \% .^{2}$ Sanjay G reported incidence of Hypertensive disorders as $10.08 \%$ and Eclampsia prevalence as $1.9 \%$ among eclampsia registry patients in India. ${ }^{3}$ Incidence of pre-eclampsia was $13.85 \%$ as reported by Juhi P, and $8.95 \%$ by Yucesoy G. ${ }^{10,11}$

In our study $74.34 \%$ of the patients belonged to age group between 20-30 years. Similar findings were reported by Shrivastava A et al. (76\%) and Singh A et al. $(76.8 \%) .{ }^{12,13}$ Majority of patients $(40.35 \%)$, belonged to age group of 26-30 years. The findings of our study are consistent with the findings of the study done by Pillai SS et al.who ndings are similardocumented $42.72 \%$ patients in the age group of $26-30$ years. ${ }^{4}$ These findings are related to the fact that most women conceive first time in this age group. ${ }^{2}$

Two third of the subjects $(69.11 \%)$ were primigravidas and approximately one third of them $(30.89 \%)$ were multigravidas. Our findings are similar to study done by Pillai et al. and Patel et al. who documented $60.90 \%$ and $71 \%$ patients in their study group being primigravidas respectively. ${ }^{4,10}$ Duckitt $\mathrm{K}$ reported nulliparity as one of the risk factors in their systemic review of risk factors for preeclampsia. ${ }^{7}$ Frequent occurrence of pre-eclampsia in primigravidas may be related to failure of normal invasion of trophoblastic cells leading to maladaptation of spiral arterioles. ${ }^{13}$

In our study $68.04 \%$ cases were either referred or unbooked and $31.96 \%$ were booked patients. Findings of our study are similar to the findings of study done by Raji C. et al. $(68.49 \%)$ and Patel J. et al. $(68.75 \%) .{ }^{5,10}$ This could be attributed to the lack of proper antenatal care and follow up. $^{2}$

In present study $84.29 \%$ cases presented at gestational age between $29-36$ weeks, $6.58 \%$ patients presented at $<28$ weeks gestation and $9.12 \%$ patients presented at $>37$ weeks gestation. Our study findings are consistent with the findings of study done by Patel J. et al. (87\% - 28-37 weeks, 4\% $<28$ weeks and $9 \%->37$ weeks gestation)and Singh A. et al. (82.1\% - > 34 weeks, $12.5 \%$ - 30-34 weeks and 5.4\% $<30$ weeks). ${ }^{10,13}$

We observed that more than half of the patients of eclampsia had headache $(56.96 \%)$ as premonitory symptom followed by a quarter having headache and vomiting $(28.48 \%)$ as premonitory symptoms. Similar findings were found by Raji C. et al.and Shrivastava A. et al. ${ }^{5,12}$ Raji C. et al. ${ }^{5}$ found $58.20 \%$ patients having headache as premonitory symptom and $29.07 \%$ patients having headache and vomiting while Shrivastava $\mathrm{A}^{12}$ found that $58 \%$ had headache and $25 \%$ had headache and vomiting.

Though delivery is the definitive treatment of eclampsia, but convulsions do occur in post-partum period. In present study, eclampsia presented in antenatal period in $74.4 \%$ cases, intrapartun in $9.14 \%$ and post-partum in $16.46 \%$. The findings are similar to that presented by Raji et al. (77.4\% ante partum, $2.7 \%$ intra partum \& $19.9 \%$ post partum). ${ }^{5}$ Anjani et al presented more No. of antepartum cases $(92 \%)$ while review by Nobis showed $50.7 \%$ cases in antenatal period and 29.37 and $20 \%$ respectively in intrapartum $\&$ post partum period. ${ }^{2,12}$ It is difficult to differentiate between antepartum and intrapartum eclampsia. In our study increasing proteinuria was linked to increase in no. of convulsions and in turn to maternal and fetal complications.

In our study, we found that $59.22 \%$ cases had $\geq 3+$ proteinuria, $28.48 \%$ had proteinuria of $\geq 2+(87.7 \%$ patients having significant proteinuria) and only $12.3 \%$ patients had proteinuria of $\leq 1+$. Pillai SS. et al.found similar results $(58.18 \%-\geq 3+, 28.18 \%-\geq 2+$ and $13.63 \%-\leq 1+){ }^{4}$ Parmar M. et al. also documented significant proteinuria in $87 \%$ patients in their study. ${ }^{14}$ Deranged LFTs in the form of deranged SGOT and SGPT were found in $18.77 \%$ patients and deranged LDH and serum bilirubin were found in $13.59 \%$ and $14.24 \%$ patients respectively. Our study findings are similar to the findings reported by Pillai SS. et al. (Deranged SGOT and SGPT-19.09\%, deranged LDH$13.63 \%$ and deranged serum bilirubin- $14.03 \%$ cases). ${ }^{4}$ Devi SA. et al. reported deranged Liver function in $20 \%$ of cases and Singhal S. et al. in their study had deranged liver function in $20 \%$ of patients. ${ }^{15,16}$ Abnormal Renal Function Tests that is blood urea and serum creatinine were noted in $13.59 \%$ patients and raised uric acid ( $>7$ 
$\mathrm{mg} \%$ ) was noted in $15.21 \%$ patients in our study. Pillai SS. et al. observed similar findings (Raised blood urea, serum creatinine and uric acid in $13.63 \%, 15.45 \%$ and $15.45 \%$ patients respectively). ${ }^{4}$ Devi SA. et al. also reported deranged renal function in $20 \%$ of cases. ${ }^{15}$ Platelet count less than one lakh/cmm was seen in $17.80 \%$ patients and deranged PT INR in $18.77 \%$ patients. Pillai SS. et al. showed similar findings i.e. platelet count less than 1 lakh/ $\mathrm{cmm}$ in $14.54 \%$ patients and deranged PT INR in $16.36 \%$ patients. $^{4}$

In our study control of Blood pressure was achieved using Nifedipine in $38.15 \%$ cases, Labetalol in $29.77 \%$ patients, $24.31 \%$ patients required Nifedipine with Labetalol and in only $7.77 \%$ patients Nifedipine with Alpha Methyl Dopa was used. Similar findings were stated by Pillai SS et al.i.e. use of Nifedipine in 39.09\%, Labetalol in $28.18 \%$, Nifedipine with Alpha Methyl Dopa in $8.18 \%$ and Nifedipine with Labetalol in $24.54 \%$ cases. ${ }^{4}$

As the definitive treatment of eclampsia is delivery; $60.19 \%$ eclampsia patients were delivered by Cesarean compared to $42.03 \%$ pre-eclampsia patients. $35.92 \%$ eclampsia patients were delivered vaginally compared to $57.97 \%$ pre-eclampsia patients $(\mathrm{p}=<.00001) .3 .24 \%$ and $2 \%$ of the eclampsia patients delivered by assisted vaginal delivery and by hysterotomy respectively. Our findings are similar to the findings of Raji C. et al. who reported LSCS in $61.65 \%$, normal vaginal delivery in $33.51 \%$, Assisted instrumental vaginal delivery in $3.42 \%$ and hysterotomy in $0.68 \%$ cases and Pillai et al.(LSCS in $64.54 \%$ cases, normal vaginal delivery $-28.18 \%$, Assisted vaginal delivery - $4.54 \%$ and hysterotomy in $2.72 \%$ cases. ${ }^{4,5}$ Most common indication for Caesarean section was previous LSCS $(37.61 \%)$, followed by unfavourable cervix $(31.88 \%)$, failed induction (13.82\%), Doppler abnormalities $(8.97 \%)$, Cephalo-Pelvic Disproportion (CPD) (4.73\%) and abruptio placentae $(2.99 \%)$. The higher rate of Caesarean section in eclampsia is due to early delivery approach to prevent further maternal and fetal complications especially when the cervix was unfavourable for induction.

In spite of early delivery, maternal complications were seen in $21.68 \%$ cases. Maternal complications in present study are compared with complications in earlier studies as shown in Table 11. We also observed that increasing poteinuria had significant corelation to maternal complications $(\mathrm{p}$ value $=.006398)$

There were 4 maternal deaths $(1.3 \%)$ during the study period due to eclampsia and related complications. Madhuri CH. et al., Patel J. et al. and Yucesoy G. et al. documented $1.3 \%, 2 \%$ and $1.17 \%$ maternal deaths respectively in their studies. ${ }^{8,10,11}$

With ragards to fetal outcomes, it was observed that $68.09 \%$ babies had birth weight $<2.5 \mathrm{~kg}$. Our findings are similar to study done by Raji $\mathrm{C}$ et al.wherein they reported $60 \%$ babies having birth weight less than $2.5 \mathrm{~kg}$ and Joshi
P. et al.observed $68.54 \%$ babies with birth weight of $<2.5$ kg. 5,17

$19.41 \%$ babies had perinatal complications. Perinatal complications also had significant corelation to increasing proteinuria $(\mathrm{p}=<.00)$. Prematurity was the most common perinatal complication. Our findings are similar to that reported by Raji C et al. ${ }^{5}$

Perinatal mortality was found to be $18 \%$ (6.98\% neonatal deaths and $11.03 \%$ still births). Our findings are similar to the results reported by Pillai SS. et al and Madhuri $\mathrm{CH}$. et al. who reported Perinatal mortality of $18 \%$ each. $^{4,8}$

The incidence of eclampsia was analysed over 4 years. There was no significant change in the incidence of eclampsia over four years. Nobis et al. also reported that there is no reduction in incidence of eclampsia in India over the decades. ${ }^{2}$ It is appropriate to mention that our data is hospital based and hence does not reflect the entire population. Also following introduction of National Rural Health Mission (NRHM) and Government of India's Policy regarding hospital delivery, there is increase in the number of hospital delivery and that of eclampsia in hospital practice. Eclampsia usually follows preeclampsia; to prevent eclampsia, preeclampsia has to be prevented. Results of randomized clinical trials using different pharmacological agents failed to show definite benefit in preventing preeclampsia. Rate of eclampsia can be reduced with use of prophylactic magnesium sulfate. Findings of the Magpie Trial revealed that in women with imminent eclampsia the number of women to be treated to prevent one case of eclampsia was 36 , and in those without symptoms the number of women to be treated to prevent one eclampsia was $129 .^{2}$

\section{Conclusion}

Pre-eclampsia is one of the medical complications which occur during pregnancy and is responsible for significant feto-maternal morbidity and mortality. As pre-eclampsia cannot be fully prevented, diagnosis of high-risk patients and timely treatment can help prevent complications. As exact etiopathology of pre-eclampsia is still unknown more research is needed in understanding pre-eclampsia to plan effective strategy for predicting as well as preventing adverse outcomes. Education and empowerment of women is need of the hour. As doctor to patient ratio is below par, the role of ASHA workers is important. Government efforts to track all pregnancies will ensure adequate antenatal care especially to the socio-economically deprived and rural population. Incidence of eclampsia in India is remaining same over the decades though maternal mortality has shown slight reducing trend. Unchanged incidence is likely to be influenced by social adversities. Use of MgSO4 in all cases of eclampsia may reduce the death rate. $\mathrm{MgSO} 4$ should be used in all cases of imminent eclampsia to avoid missed opportunities. Doctors working in peripheral 
Table 11: Comparison of maternal complications inpresent study versus earlier studies

\begin{tabular}{lcccc}
\hline $\begin{array}{l}\text { Maternal } \\
\text { Complication }\end{array}$ & Raji C. et al $^{\mathbf{5}}$ & Madhuri Ch. et al $^{\mathbf{8}}$ & Yucesoy G. et al $^{\mathbf{1 1}}$ & Present study \\
ARDS & $5.47 \%$ & $0.76 \%$ & $0.39 \%$ & $0.65 \%$ \\
Pulmonary edema & $1.36 \%$ & - & $0.78 \%$ & $1.29 \%$ \\
DIC & $0.68 \%$ & $0.8 \%$ & $2.35 \%$ & $0.97 \%$ \\
Renal failure & $2.05 \%$ & $0.57 \%$ & $2.35 \%$ & $1.94 \%$ \\
Abruptio placentae & $4.10 \%$ & - & $7.5 \%$ & $3.83 \%$ \\
HELLP syndrome & $3.42 \%$ & $4.91 \%$ & $2.35 \%$ & $5.83 \%$ \\
ARF with DIC & $0.68 \%$ & - & - & $0.64 \%$ \\
HELLP with IVH & $0.68 \%$ & - & - & $0.68 \%$ \\
HELLP with ARF & $1.36 \%$ & - & - & $1.29 \%$ \\
PPH & - & $6.53 \%$ & & $4.53 \%$ \\
\hline
\end{tabular}

Table 12: Comparison of perinatal complications inpresent study versus study by Raji C. et al ${ }^{5}$

\begin{tabular}{lcc}
\hline Perinatal complications & Raji C. et al & Present study $^{\mathbf{5}}$ \\
1. Prematurity & $41.4 \%$ & $40 \%$ \\
2. Respiratory Distress Syndrome & $31 \%$ & $29.86 \%$ \\
3. Birth Asphyxia & $13.8 \%$ & $13.04 \%$ \\
4. IUGR/ MAS & $13.8 \%$ & $17.10 \%$
\end{tabular}

hospitals and midwives should have periodic training in the management of preeclampsia and eclampsia to avoid missed opportunities as well as better transport facilities are required to handle obstetric emergencies.

\section{Source of Funding}

Nil.

\section{Conflict of Interest}

None declared.

\section{References}

1. Saxena N, Bava A, Nandanwar Y. Maternal and perinatal outcome in severe preeclampsia and eclampsia. Int J Reprod Contracept Obstet Gynecol. 2016;5:2171-6. [oi:10.18203/2320-1770.1jrcog20162086

2. Nobis PN, Hajong A. Eclampsia in India Through the Decades. $J$

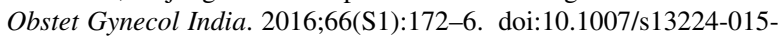
D80[-5.

3. Wagh SS, Kulkarni AP, Sargade VG. Machinability Studies of Austenitic Stainless Steel (AISI 304) Using PVD Cathodic Arc Evaporation (CAE) System Deposited AlCrN/TiAlN Coated Carbide Inserts. Procedia Eng. 2013;64(1):907-14. doi:10.1016/1.proeng.2013.09.167.

4. Pillai SS. Fetomaternal outcome in severe preeclampsia and eclampsia: a retrospective study in a tertiary care centre. Int J Reprod Contracept Obstet Gynecol. 2017;6:3937-41.

5. Raji C, Poovathi M, Nithya D. Prospective study of fetomaternal outcome in eclampsia in a tertiary care hospital. Int $J$ Reprod Contracept Obstet Gynecol. 2016;5:4329-34.

6. Tranquilli AL, Dekker G, Magee L, Roberts J, Sibai BM, Steyn $\mathrm{W}$, et al. The classification, diagnosis and management of the hypertensive disorders of pregnancy: A revised statement from the ISSHP. Int J Women's Cardiovasc Health. 2014;4:97-104. do1:10.1016/1.preghy.2014.02.001

7. Dukkit K, Harrington D. Risk factors for preeclampsia at antenatal booking: systemic review of controlled studies. BMJ. 2005;330(7491):565.
8. Madhuri $\mathrm{CH}$, Varalakshmi Y. Retrospective study on fetomaternal outcome in gestational hypertension, pre eclampsia and eclampsia in a tertiary care centre. Indian J Basic Appl Med Res. 2019;8(4):246-55.

9. Cunningham FG, Lenevo KJ, Bloom SL, Hauth JC, Rouse DJ, Catherine YS. Williams Obstetrics. 24th ed. New York: Mc Graw Hill Companies; 2014.

10. Patel J. Study of Fetomaternal Outcome in Cases of Preeclampsia. Int J Sci Res. 2015;4(7):503-5.

11. Yucesoy G, Ozkan S, Bodur H, Tem T, Cahskan E, Vural B, et al. Maternal and perinatal outcome in pregnancies complicated with hypertensive disorder of pregnancy: a seven year experience of a tertiary care center. Arch Gynaecol Obstet. 2005;273:43-9.

12. Shrivastava A. Feto-Maternal Outcome in Women with Early Onset of Pre-Eclampsia and Eclampsia. Int J Sci Res. 2017;6(8):13-7.

13. Singh A, Chawla S, Pandey D, Jahan N, Anwar A. Fetomaternal Outcome in Cases of Pre-eclampsia in a Tertiary Care Referral Hospital in Delhi, India: A Retrospective Analysis. Int J Sci Stud. 2016;4(2):100-3.

14. Parmar MR, Vaja P. Effect of pregnancy induced hypertension on maternal and perinatal outcome at tertiary care center in Ahmedabad, Gujarat, India. Int J Reprod Contracept Obstet Gynecol. 2017;6(10):4661. do1:10.18203/2320-17/0.1]rcog20174460.

15. Devi SA, Chandana MP, Sailakshmi M. Maternal and Perinatal Outcome in Severe Pre-eclampsia and Eclampsia in Rajarajeswar Medical College, Bangalore. Int J Sci Stud. 2019;7(1):19-21.

16. Singhal S, Deepika A, Nanda S. Maternal and perinatal outcome in severe preeclampsia and eclampsia. S Asian Fed Obstet Gynecol. 2009;1:25-33.

17. Joshi P, Kathaley M, Borade S, Dashrathi R. Maternal and Perinatal Outcome in Hypertensive Disorders of Pregnancy - A Retrospective Study. MVP Journal of Medical Sciences. 2018;5(1):8791-8791.

\section{Author biography}

Manjusha Jindal, Associate Professor \& Unit Head

Dweep Jindal, Ex-Senior Resident, Associate Consultant

Viraj Naik, Senior Resident 
Mrinalini Sahasrabhojanee, Assistant Professor

Guruprasad Pednekar, Professor and Head
Cite this article: Jindal M, Jindal D, Naik V, Sahasrabhojanee M,

Pednekar G. Epidemiology and fetomaternal outcomes in cases of imminent eclampsia and eclampsia- retrospective study. Indian J Obstet Gynecol Res 2021;8(1):39-48. 